
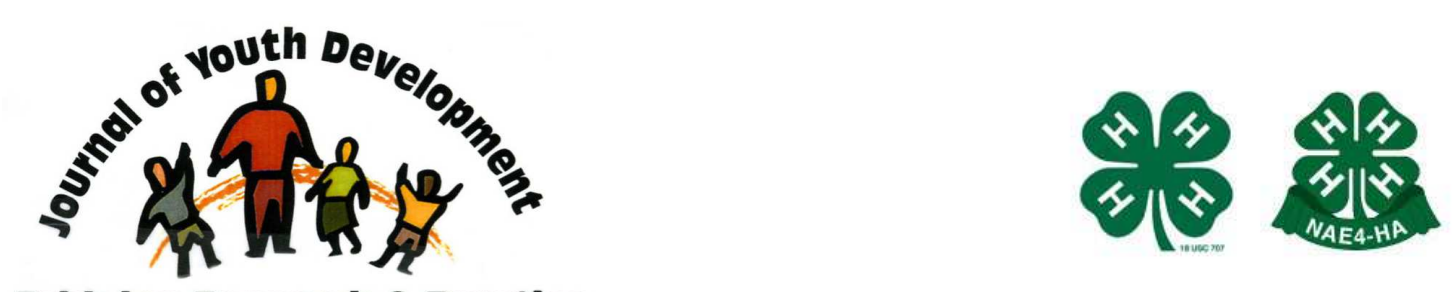

Bridging Research \& Practice

\title{
4-Health: A Programmatic Evaluation of a Parent-Based Childhood Obesity Prevention Program
}

\author{
Carrie Benke \\ 4-Health Project \\ Montana State University Extension \\ carrie.benke@montana.edu \\ Sandra Bailey \\ Department of Health and Human Development \\ Montana State University \\ baileys@montana.edu \\ Galen Eldridge \\ 4-Health Research \\ Montana State University Extension \\ galen.eldridge@montana.edu \\ Wesley Lynch \\ Department of Psychology \\ Montana State University \\ wlynch@montana.edu \\ Jill Martz \\ Montana State University Extension \\ jmartz@montana.edu \\ Lynn Paul \\ Department of Health and Human Development \\ Montana State University \\ Ipaul@montana.edu
}




\title{
JOURNAL OF YOUTH DEVELOPMENT \\ bridging research and practice

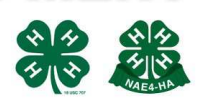

Volume 8, Number 3, Winter 2013

Article 130803FA002

\section{4-Health: A Programmatic Evaluation of a Parent-Based Childhood Obesity Prevention Program}

\author{
Carrie Benke, Sandra Bailey, Galen Eldridge, Wesley Lynch, Jill Martz and Lynn Paul \\ Montana State University
}

\begin{abstract}
The 4-Health Project promotes healthy lifestyles for rural families with an overall goal of reducing or preventing childhood obesity. 4-Health is an integrated research and educational outreach program delivered by agents located in Montana State University Extension offices throughout the state. The collaborative project was developed to provide healthy living programs focusing on the areas of parenting and family communication, body image, food and nutrition, and physical activity to rural parents of 8-12 year old children participating in Montana's 4-H Youth Development programs. Evaluation outcomes of the 4-Health Educational (experimental) program and the Healthy Living Information (control) program both showed increases in participants' knowledge, attitudes, and behaviors related to healthy living, with those participating in the 4-Health Educational program making greater gains.
\end{abstract}

\section{Introduction}

Childhood obesity continues to be a nationwide concern, as approximately one in three children is overweight or obese (Ogden, Carroll, Curtin, Kit, \& Flegal, 2012). Recent studies indicate that obesity rates for children in rural settings are as high as or higher than that of their urban counterparts (Davis, Bennett, Befort, \& Nollen, 2011). During the preteen years, parents have the ability to greatly impact food and nutrition choices, physical activity levels, and socioemotional development of their children, giving them an important role in the development of their children's behavior related to healthy living and the prevention of weight-related problems (Golan, \& Crow, 2004; Rhee, 2008). Because parents play such an important role in the lives of their preteen children, the focus of this research and educational outreach program was to develop an evidence-based educational program to improve the health and quality of life of rural children and families. A review of existing programs was done to assist in program 
development. Current research suggests that effective family-based interventions include modifications for the home environment, parental role modeling of healthy behaviors, parental encouragement and support for healthy behaviors in children, and using goal setting as a means to create behavior change (Bauer, Berge, \& Neumark-Sztainer, 2011; Golley, Hendrie, Slater, \& Corsini, 2011).

To address childhood obesity from a family influence perspective, the Montana State University 4-Health Project was created by an interdisciplinary team including a Professor of Psychology, the Extension Food and Nutrition Specialist, the State 4-H Director, and the Extension Family and Human Development Specialist. A project director, hired to oversee the 4-year project, and a research assistant rounded out the team after funding was acquired from the United States Department of Agriculture, National Institute of Food and Agriculture.

The 4-Health Project aims to promote healthy lifestyles for rural families and was developed to meet the specific needs of rural parents of 8-12 year old 4-H members. The 4-Health Project consists of integrated research and outreach components delivered by agents located in Extension Offices in rural Montana counties. In order to evaluate the effectiveness of 4-Health, a pre-test/post-test design with an intervention and control group was developed.

The 4-Health Educational program was the intervention program aimed at promoting healthy lifestyles among rural Montana families through participation in 10, ninety-minute, face-to-face sessions taught by a Montana State University Extension Agent in each participating county. The Healthy Living Information program was delivered to participants in other counties and consisted of mailed packets of information corresponding to topics similar to those in the experimental program. The evaluation research hypothesis stated that parents in the 4-Health Educational program would show significantly greater improvements in reported knowledge, attitudes, and family health-related behavior changes pre- to post-intervention than parents in the Healthy Living Information program.

The 4-Health Project had three overarching research goals:

- Develop an effective parent-centered obesity prevention educational program that changes the knowledge, attitudes, and behaviors of rural families in order to promote health and well-being while preventing or reducing childhood obesity.

- Implement the 4-Health Educational program (and a Healthy Living Information program) over an 8-month period by offering it to parents of 8-12 year old children who are currently participating in Montana's 4-H Youth Development programs.

- Evaluate participants' self-reported knowledge, attitudes, and behaviors before and after the programs in order to determine effectiveness of the 4-Health Educational program on family healthy living habits versus the Healthy Living Information program.

\section{Methodology}

The 4-Health Project was developed over several phases. Prior to implementing the project, focus groups (Phase 1) were conducted and a pilot study was carried out in three experimental and three control counties located across the state (Phase 2). These components assisted the team in the development of the final version of the 4-Health curriculum and the identification of written materials for the Healthy Living information program. In Phase 3 the program was implemented in 21 counties (11 experimental, 10 control). 
Program sites for Phase 3 were selected in a semi-random, regional cluster design process in which county Extension Agents were recruited to host a program and were assigned to a group based on both their preference to be in either the experimental or control group, if needed, and their geographic location. This assignment strategy allowed for some regional matching of experimental and control groups to ensure statewide participation in both treatment conditions. A true random assignment was not possible because we did not have the authority to require Extension Agents to participate in the study. The 4-Health Educational program was delivered during face-to-face meetings over an 8-month period between September 2011 and April 2012 to the experimental group. Packets of information that made up the Healthy Living Information program were mailed to the control group participants at specific intervals during the same time frame.

Participants' knowledge, attitudes, and behaviors were assessed through a retrospective preand post-program evaluation for the experimental and control groups. Nineteen quantitative questions and four open-ended qualitative questions were used that focused on specific knowledge, attitudes, and behaviors relating to the four program focus areas: parenting and family communication, body image, food and nutrition, and physical activity. Quantitative data were managed using the SPSS statistical package (v.20). Confirmatory factor analysis and repeated-measures ANOVAs were used to analyze the quantitative data. Qualitative data were managed using MS Word processing and were independently hand coded by four team members. The codes were entered into SPSS and an inter-rater reliability check was conducted.

\section{Sample}

The sample was drawn from 4-H families in Montana. Participants were parent and youth dyads, with the youth being a 4-H between the ages of 8 and 12 at the start of the study. There were 194 parent-child dyads that began the program during the pilot and full year combined. Of the 169 parents who completed the evaluation, 91 were participants from the experimental group and 78 were participants from the control group. The average age of parent participants was 41.0 years. The average age of youth participants was 10.7 years. Further participant demographics of dyads that completed the project are shown in Table 1. 
Table 1

Sample demographics N = 169 Parents/169 Youth

\begin{tabular}{|l|c|}
\hline \multicolumn{1}{|c|}{ Variable } & $\%$ \\
\hline Parent Gender & $3.4 \%$ \\
\hline Male & $96.6 \%$ \\
\hline Female & \\
\hline Child Gender & $34.6 \%$ \\
\hline Male & $65.4 \%$ \\
\hline Female \\
\hline Parent Ethnicity or Race \\
\hline White or Caucasian \\
\hline American Indian or Alaskan Native & $97.8 \%$ \\
\hline Other & $0.6 \%$ \\
\hline Child Ethnicity or Race & $1.7 \%$ \\
\hline White or Caucasian & $98.3 \%$ \\
\hline American Indian or Alaskan Native & $0.6 \%$ \\
\hline Other & $1.1 \%$ \\
\hline Family Income & $2.8 \%$ \\
\hline Less than $\$ 14999$ & $4.5 \%$ \\
\hline$\$ 15000$ to $\$ 24999$ & $7.4 \%$ \\
\hline$\$ 25000$ to $\$ 34999$ & $23.3 \%$ \\
\hline$\$ 35000$ to $\$ 49999$ & $31.8 \%$ \\
\hline$\$ 50000$ to $\$ 74999$ & $18.8 \%$ \\
\hline$\$ 75000$ to $\$ 99999$ & $11.4 \%$ \\
\hline$\$ 100000$ or more & \\
\hline
\end{tabular}

\section{Quantitative Results}

Data were collected retrospectively from all parent participants following completion of the postintervention sessions of the pilot and full study. The 4-Health Final Participant Evaluation form included 17 questions in the pilot study and 19 questions in the full study. The two questions that were added concerned the focus area of physical activity. The two new questions addressed family communication related to physical activity and taking advantage of community sites for physical activity. The evaluation form covered the four program areas of being an active parent (AP), body image (BI), food and nutrition (FN), and physical activity (PA). Parents were asked to rate each item twice, once for the period prior to the program (pre) and once for the period following the program (post). Ratings in both cases were on a 5-point Likert scale ranging from strongly disagree (1) to strongly agree (5).

During preliminary analysis of individual items in the quantitative questionnaire a consistent pattern emerged for each group of questions, suggesting a high degree of correlation among items within each of the four focus areas covered. As a result, a factor analysis of all items (using pre-intervention data for all participants) was carried out prior to further analysis. This analysis confirmed the existence of four factors (Eigenvalues $>1.0$ ) corresponding to the four topic areas. Using mean scores for each of the four areas, separate mixed-model ANOVAs were carried out, with group (experimental versus control) as the between-subjects factor and preand post-program evaluations as the within-subjects factor.

For all composite scores, the pre- to post- program improvement was greater in the 4-Health Educational (experimental) program than in the Healthy Living Information (control) program, demonstrating greater reported increases in knowledge and healthy behaviors among participants in the face-to-face 4-Health Educational (experimental) program. 


\section{Being an Active Parent}

The mean factor score for being an active parent, using a 5-point Likert scale ranging from strongly disagree (1) to strongly agree (5), consisted of participants' responses to the following statements:

- I could use good communication skills when interacting with my family.

- I could provide high levels of love and warmth.

- I could provide appropriate boundaries based on my child's age.

- I could advocate for my preteen when needed.

- I could provide opportunities for my preteen to grow and develop his/her own identity.

Figure 1. Mean response to active parenting statements.

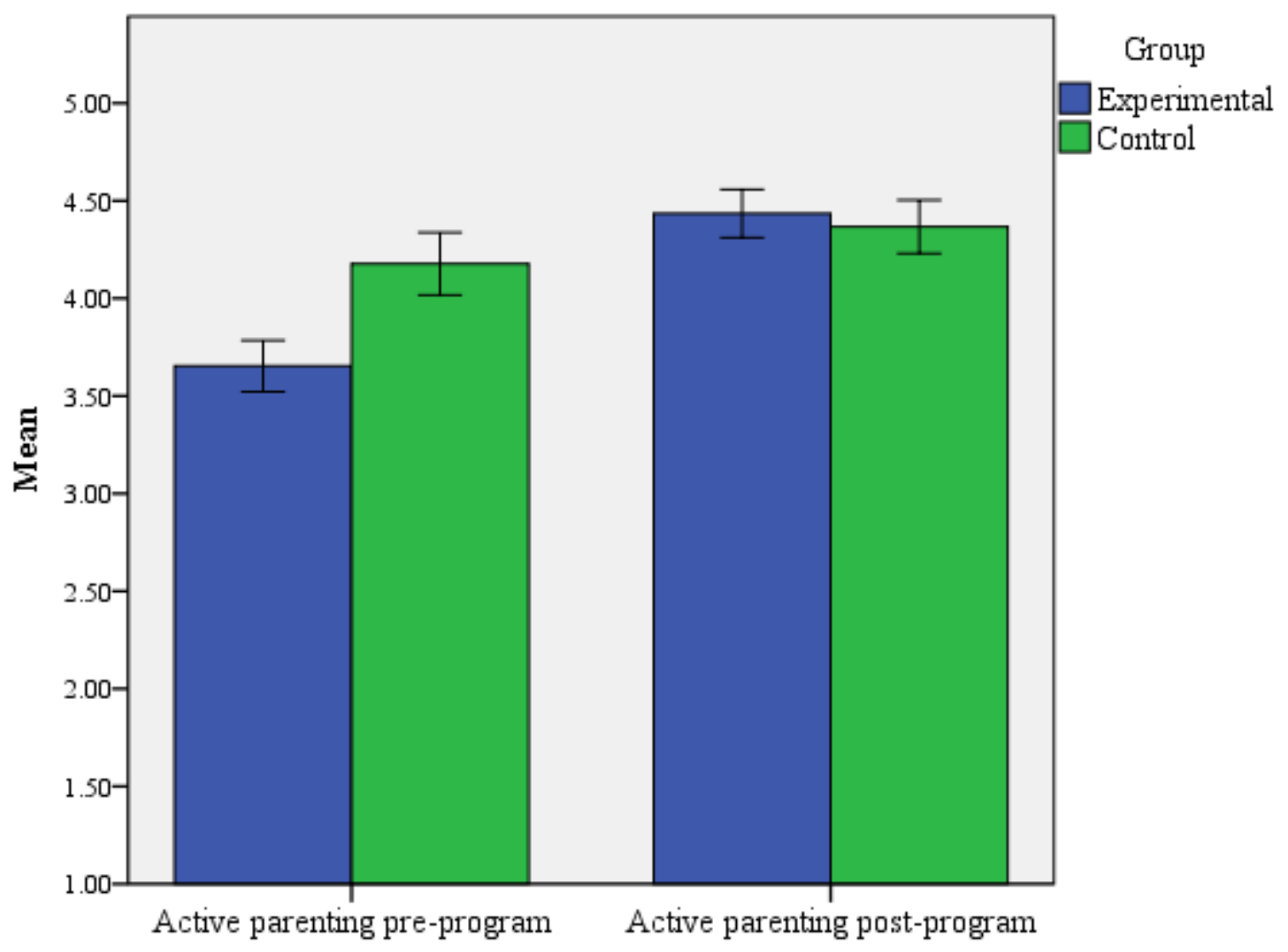

Error Bars: +/- $2 \mathrm{SE}$

Results, as shown in Figure 1, indicated a significant pre- to post-program change in parents' reports of practicing active parenting $(p<.001)$, showing that both groups reported an increase. There was a significant pre- to post-program change $x$ experimental/control interaction $(p<.001)$, showing that the experimental group reported greater pre- to postprogram change than the control group.

\section{Body Image}

The body image factor score consisted of participants' responses to the following statements:

- Our family could focus on each individual's positive traits and capabilities. 
- Our family could encourage size and body acceptance of self and others.

- Our family could understand media and the environmental influences on the development of body image.

- Our family could teach and model healthy self-esteem, respect, and confidence.

Figure 2. Mean response to body image statements.

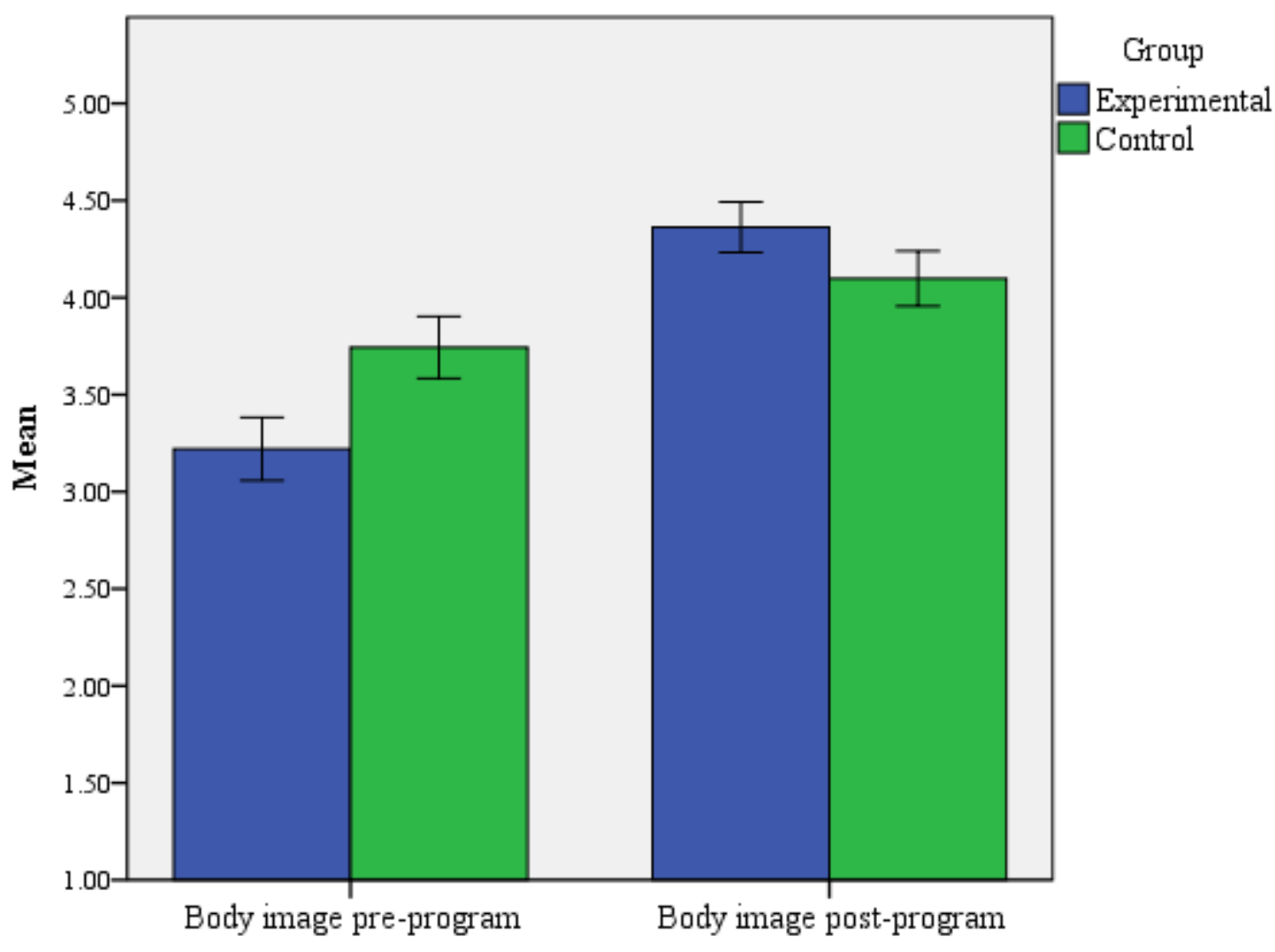

Error Bars: +/- $2 \mathrm{SE}$

As can be seen in Figure 2, there was a significant pre- to post-program change in parents' reported enhancing of positive body image $(p<.001)$, showing that both groups increased. There was a significant pre- to post-program change $x$ experimental/control interaction $(p<$ .001 ), showing that the experimental group reported greater pre- to post-program change than the control group.

\section{Food and Nutrition}

The food and nutrition factor score consisted of participants' responses to the following statements:

- Our family could choose foods and beverages packed with nutrients.

- Our family could eat meals and snacks regularly.

- Our family could choose food portions appropriate for our activity level.

- Our family could eat together regularly.

- Our family could practice the principles of normal, healthy eating.

- Our family could avoid unhealthy weight control practices. 
Figure 3. Mean response to food and nutrition statements.

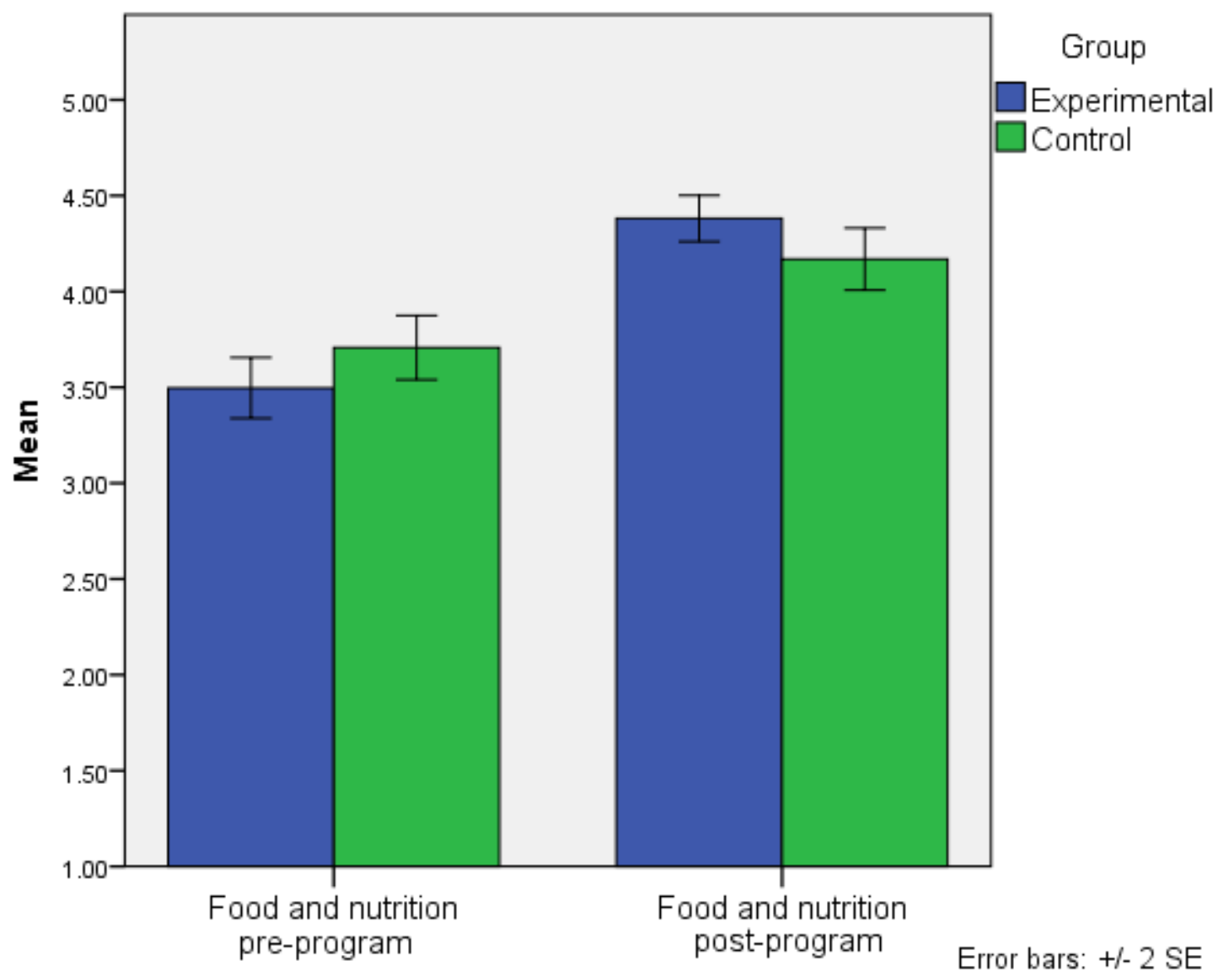

Similar to the findings for active parenting and body image, Figure 3 shows, there was a significant pre- to post-program change in parents' reported enhancing of healthy food and nutrition behaviors $(p<.001)$, showing that both groups reported increases. There was again a significant pre- to post-program change $x$ experimental/control interaction $(p<.001)$, showing that the experimental group reported greater pre- to post-program change than the control group.

\section{Physical Activity}

The physical activity factor score consisted of participants' responses to the following statements:

- Our family could work to create an accessible environment that promotes an active lifestyle.

- Our family could work to reduce sedentary time.

- Our family could promote physical activity through family communication.

- Our family could take advantage of community sites that provide places for physical activity. 
Figure 4. Mean response to physical activity statements.

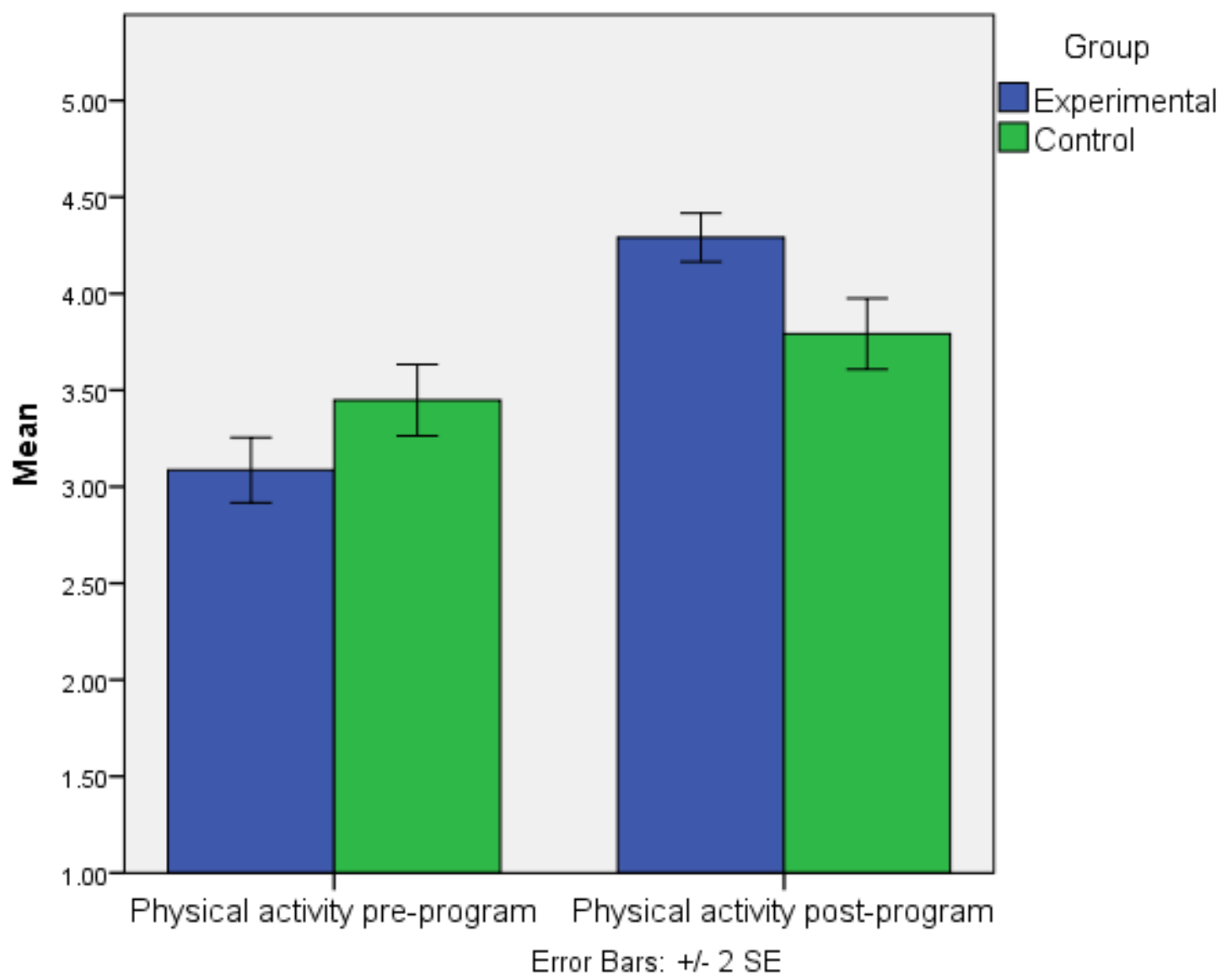

The results shown in Figure 4 for physical activity showed there was a significant pre- to postprogram change in engaging in a physically active lifestyle $(p<.001)$, showing that both groups reported increases. There was a significant pre- to post-program change $x$ experimental/control interaction $(p<.001)$, showing that the experimental group reported greater pre- to post-program change than the control group.

\section{Qualitative Results}

In addition to the quantitative portion of the evaluation, four open-ended evaluation statements were posed about potential changes that parents had made after participating in either program. The four statements addressed the areas of focus: parenting, body image, food and nutrition, and physical activity.

- As a result of this program, describe what you have done to become a more active parent.

- As a result of this program, describe how your family has worked to enhance positive body image.

- As a result of this program, describe how your family has changed their food and nutrition behavior.

- As a result of this program, describe how your family has made changes to engage in a more physically active lifestyle. 
The qualitative responses from the parents were analyzed using an analytic induction approach. According to Patton (2002), qualitative research can be deductive in nature, where the researcher analyzes data to confirm or verify an existing theoretical framework. As Patton notes, qualitative analysis can first be deductive followed by (or alongside) an inductive process. In this way, a researcher begins by examining the data in terms of "theory-derived sensitizing concepts" or applying an existing framework (p. 454). During this deductive phase, the researcher can simultaneously search for emergent patterns by using an inductive process. The 4-Health Team selected knowledge, attitude, and behavior (KAB) to apply in the analysis. The KAB has been used in nutrition and health related studies and evaluations (Baranowski, Cullen, Nicklas, Thompson, \& Baranowski, 2003; Brown, \& Kiernan, 1998; Lin, Yang, Hang, \& Pan, 2007). The KAB model was operationalized using the following:

$\mathrm{K}$ - (Knowledge) Understanding of information

A - (Attitude) Belief about the value of the information

$\mathrm{B}$ - (Behavior) Application of knowledge gained from the information; action taken

Four members of the 4-Health team coded the responses using the KAB model to explore possible changes in knowledge, attitudes, and behaviors that participants reported. After the independent coding was completed two of the team members compiled the responses. It was noted that the way in which the open-ended questions were worded did not prompt responses related to attitude as was assessed by the Likert scale questions, therefore no 'A's were coded. Next, team members found that numerous participant responses used the term "trying" or "tried." For example, in response to the question about changes in being more physically active after participating in the program one parent responded, "As a result of this program, we try to individually and as a family get out and get moving more often. We each have our own exercise program but we also like to do things as a family." In responses that used the terms "trying" or "tried," it was difficult for the team to determine if the respondents had actually moved to making a change in behavior. Therefore, responses referencing "trying" or "tried" were coded as KB, meaning that the participant had gained knowledge but it was not clear whether or not the participant had changed his/her behavior.

As a result of these adaptations most responses were coded as KB (trying to make a change) or $B$ (behavior change). After the two changes were made in the coding the inter-rater reliability was computed. Inter-rater reliability was .87 for the experimental group and .86 for the control group. This inter-rater reliability was very conservative. If only one of the four team members had a different rating on an item, the item was marked as inconsistent. Table 2 below provides a sample of participant responses to each of the evaluation statements. As can be seen, the responses to the open-ended statements supported the quantitative results of the evaluation. 
Table 2

Examples of participant qualitative responses

\begin{tabular}{|c|c|}
\hline Evaluation Statement & Example Participant Responses \\
\hline $\begin{array}{l}\text { As a result of this program, } \\
\text { describe what you have done to } \\
\text { become a more active parent. }\end{array}$ & $\begin{array}{l}\text { "We do things with the children instead of telling them to do } \\
\text { physical activity, realizing that we are their most important } \\
\text { role models." } \\
\text { "I'm involving my kids more in cooking and making some of } \\
\text { the choices, offering healthier snack options and discussing } \\
\text { why we need to make these changes." }\end{array}$ \\
\hline $\begin{array}{l}\text { As a result of this program, } \\
\text { describe how your family has } \\
\text { worked to enhance positive body } \\
\text { image. }\end{array}$ & $\begin{array}{l}\text { "I am way more conscious of it [body image] and do way } \\
\text { more to promote positive body image - we really try to watch } \\
\text { what we say and what we expose ourselves to." } \\
\text { "I am more aware of the way I listen to/respond to my } \\
\text { daughter's comments about her body. It's more of a } \\
\text { conversation now." }\end{array}$ \\
\hline $\begin{array}{l}\text { As a result of this program, } \\
\text { describe how your family has } \\
\text { changed their food and nutrition } \\
\text { behavior choices. }\end{array}$ & $\begin{array}{l}\text { "My family is now very aware of the importance of having a } \\
\text { plate full of color. We now use whole wheat pasta and try to } \\
\text { eat some sort of fresh vegetable or fruit daily." } \\
\text { "We are eating more and a larger variety of vegetables and } \\
\text { fruit, now everyone eats cauliflower and broccoli. The course } \\
\text { and the discussion taught me new ways to incorporate } \\
\text { vegetables into our meals." }\end{array}$ \\
\hline $\begin{array}{l}\text { As a result of this program, } \\
\text { describe how your family has made } \\
\text { changes to engage in a more } \\
\text { physically active lifestyle. }\end{array}$ & $\begin{array}{l}\text { "We have made time to walk, ride bikes, or play ball together. } \\
\text { We also found that a fun, good way to be active together } \\
\text { [inside] was to play Wii." } \\
\text { "I have decided to start dinner } 30 \text { minutes later so I can play } \\
\text { outside with the kids. We are doing things we all enjoy } \\
\text { together - and compromising on what we do. If I feel tired, I } \\
\text { try to go for a walk or bike ride with the kids." }\end{array}$ \\
\hline
\end{tabular}

When participants responses were categorized using the KAB model, both the experimental and control groups showed increases in knowledge $(K)$, attempts to change behavior (KB), and actual behavior changes (B) as a result of the program, but the experimental group consistently showed greater levels of behavior change than the control group; the control group more frequently answered that they were "trying" to change their behavior, as opposed to having actually made a change. Table 3 below provides a comparison of the percentage of participants from the experimental and control group that reported no changes, acquired knowledge, attempts to change behaviors, and actual changes in behavior. 
Table 3

Percentage of responses from participants in the experimental and control groups

\begin{tabular}{|c|c|c|c|c|}
\hline $\begin{array}{c}\text { As a result of this program } \\
\text { describe... }\end{array}$ & $\begin{array}{l}\text { Reported } \\
\text { no change }\end{array}$ & $\begin{array}{c}\text { Acquired } \\
\text { knowledge }\end{array}$ & $\begin{array}{c}\text { Are trying to } \\
\text { change } \\
\text { behavior }\end{array}$ & $\begin{array}{c}\text { Made } \\
\text { behavior } \\
\text { changes }\end{array}$ \\
\hline \multicolumn{5}{|l|}{$\begin{array}{l}\text {...what you have done to } \\
\text { become a more active parent. }\end{array}$} \\
\hline Experimental Group & $2.6 \%$ & $9.0 \%$ & $11.5 \%$ & $76.9 \%$ \\
\hline Control Group & $40.6 \%$ & $4.3 \%$ & $17.4 \%$ & $37.7 \%$ \\
\hline \multicolumn{5}{|l|}{$\begin{array}{l}\text {...how your family has worked } \\
\text { to enhance positive body } \\
\text { image. }\end{array}$} \\
\hline Experimental Group & $10.1 \%$ & $7.6 \%$ & $8.9 \%$ & $73.4 \%$ \\
\hline Control Group & $40.0 \%$ & $6.2 \%$ & $13.8 \%$ & $40.0 \%$ \\
\hline \multicolumn{5}{|l|}{$\begin{array}{l}\text {...how your family has changed } \\
\text { their food and nutrition } \\
\text { behavior choices. }\end{array}$} \\
\hline Experimental Group & $0 \%$ & $2.3 \%$ & $3.5 \%$ & $94.2 \%$ \\
\hline Control Group & $17.6 \%$ & $5.9 \%$ & $20.6 \%$ & $55.9 \%$ \\
\hline \multicolumn{5}{|l|}{$\begin{array}{l}\text {... how your family has made } \\
\text { changes to engage in a more } \\
\text { physically active lifestyle. }\end{array}$} \\
\hline Experimental Group & $2.8 \%$ & $4.3 \%$ & $20.0 \%$ & $72.9 \%$ \\
\hline Control Group & $32.1 \%$ & $5.4 \%$ & $23.2 \%$ & $39.3 \%$ \\
\hline
\end{tabular}

The 4-Health Team followed up with participants from the full study with final evaluations 6 months after the post program evaluation. Although only two-thirds of the participants from the full study year were able to complete the follow up evaluation, $92.8 \%$ of respondents in the 4-Health Educational program group reported having continued with changes they made in the areas of parenting, body image, food and nutrition, and physical activity. In contrast, only $57 \%$ of parents in the Healthy Living Information group reported continuing with changes they made in the same areas.

\section{Discussion, Conclusions, and Implications for Practice}

The evaluation findings show that although participants in both groups improved their knowledge and behaviors related to parenting, body image, food and nutrition, and physical activity within their families, the participants in the 4-Health Educational (experimental) program reported a significantly greater level of learning and behavior change than the participants in the Healthy Living Information (control) program. In other words, participants who were given the opportunity for face-to-face facilitated sessions with peer interaction reported greater improvements in knowledge and behaviors than participants who only received healthy living written materials. These findings contribute to the body of knowledge that 
suggests even though health information is widely available through many media sources, Extension's facilitated programming efforts, especially in rural areas, are a more effective method of providing education that has a significantly greater impact on participants than educational materials alone.

Feedback from program participants and facilitators of the 4-Health Educational program on components of the program that had the most impact on them was provided to the 4-Health Team. The following suggestions may be helpful to Extension educators and those providing face-to-face healthy living programs to $4-\mathrm{H}$ families or other parents:

- Provide Time for Interaction - In addition to finding the content of the program valuable, participants found great value in having time, as parents, to talk about what was going on with their families, in their homes, and in their communities. Most participants mentioned the social support of the other parents in their group as one of the highlights of the 4-Health Educational program, especially during discussions on topics that were newer to them, such as body image.

- Provide Healthy Snacks - Participants appreciated when healthy snacks were provided by facilitators, especially when new foods were introduced, such as quinoa, couscous, or seasonal fruits and vegetables. The introduction of these foods during sessions increased participant confidence in serving them at home.

- Provide Family Friendly Recipes with Take-Home Ingredients - Participants enjoyed takehome recipes and simple, healthy ingredients provided by facilitators for engaging their preteen in the kitchen. It encouraged them to try new foods at home and spend time with their families discussing healthy living topics.

- Provide Physical Activity Breaks Mid-Session - Participants appreciated an activity break mid-session, especially when activities that were new to them were incorporated, such as strength training exercises or yoga poses. They also enjoyed sharing ideas for activities that they could use with their families at home during the cold winter months, such as having at home "dance parties" or sharing local community opportunities for family fun and fitness.

The 4-Health Educational Program will continue to be facilitated across Montana in 2013-2014. The program materials are currently being disseminated statewide and are available for download at www.4health.org.

\section{References}

Baranowski, T., Cullen, K.W., Nicklas, T., Thompson, D., \& Baranowski, J. (2003). Are current health behavioral change models helpful in guiding prevention of weight gain efforts? Obesity Research, 11, 23S-43S.

Bauer, K.W., Berge, J.M., \& Neumark-Sztainer, D. (2011). The importance of families to adolescents' physical activity and dietary intake. Adolescent Medicine, 22(3). 601-613.

Brown, J.L., \& Kiernan, N.E. (1998). A model for inegrating program development and evaluation. Journal of Extension, [On-line], 36(3), Article 3RIB5. Available at http://www.joe.org/joe/1998june/index.php. 
Davis, A.M., Bennett, K.J., Befort, C., Nollen, N. (2011). Obesity and related health behaviors among urbank and rural children in the United States: Data from the National Health and Nutrition Examination Survey 2003-2004 and 2005-2006. Journal of Pediatric Psychology, 36(6), 669-676. doi: 10.1093/jpepsy/jsq117.

Golan, M., \& Crow, S. (2004). Parents are key players in the prevention and treatment of weight-related problems. Nutrition Reviews, 62, 39-50.

Golley, R.K., Hendrie, G.A., Slater, A., \& Corsini, N. (2011). Interventions that involve parents to improve children's weight-related nutrition intake and activity patterns - what nutrition and activity targets and behaviour change techniques are associated with intervention effectiveness? Obesity Reviews, 12(2), 114-130.

Lin, W., Yang, H., Hang, C. \& Pan, W. (2007). Nutrition knowledge, attitude, and behavior of Taiwanese elementary school children. Asia Pacific Journal of Clinical Nutrition, 16(2), 534-546.

Ogden, C.L., Carroll, M.D., Curtin, L.R., Kit, B.K., \& Flegal, K.M. (2012). Prevalence of Obesity and Trends in Body Mass Index Among US Children and Adolescents. Journal of the American Medical Association, 307(5), 483-490. doi:10.1001/jama.2012.40.

Patton, M.Q. (2002). Qualitative research and evaluation methods. (3rd ed.). Thousand Oaks, CA: Sage Publications, Inc.

Rhee, K. (2008). Childhood overweight and the relationship between parent behaviors, parenting style, and family functioning. Annals of the American Academy of Political and Social Science, 615, 12-37.

(C) Copyright of Journal of Youth Development $~$ Bridging Research and Practice. Content may not be copied or emailed to multiple sites or posted to a listserv without copyright holder's express written permission. Contact Editor at: patricia.dawson@oregonstate.edu for details. However, users may print, download or email articles for individual use.

ISSN 2325-4009 (Print); ISSN 2325-4017 (Online) 